\title{
The impact of transactional leadership on supply chain quality and performance
}

\author{
Manh Dung Trana, Thi Thu Hien Phan ${ }^{b^{*}}$, Hong Hanh Ha ${ }^{a}$ and Thi Thu Ha Hoang
}

${ }^{a}$ National Economics University, Hanoi, Vietnam

${ }^{b}$ University of Economics - Technology for Industries, 456 Minh Khai, Hai Ba Trung, Ha Noi, Vietnam

\section{H R O N I C L E}

Article history:

Received April 21, 2020

Received in revised format June

8,2020

Accepted July 112020

Available online

July 112020

Keywords:

Transactional leadership

Supply chain quality

management

Performance

Tourism

Vietnam

\section{A B S T R A C T}

The objective of this paper is to assess the impact of transactional leadership on supply chain quality management and performance in tourism and travel enterprises in Vietnam. The analysis results were conducted on 298 typical tourism and travel enterprises in Vietnam in 2019. The testing results of the hypotheses show that transactional leadership had a positive impact on supply chain quality management and performance. At the same time, supply chain quality management did not play any full mediate role in the relationship between transactional leadership and performance. However, the qualification level had a statistically significant moderate role in the relationship between transactional leadership and performance. With the more highly qualified leaders, the more transactional leadership is applied, the higher the business performance for tourism and travel enterprises in Vietnam.

(C) 2020 by the authors; license Growing Science, Canada.

\section{Introduction}

By this time, the Covid-19 epidemic had far exceeded the Sars epidemic (2002 - 2003) and MERS in the number of cases and would certainly exceed the number of deaths. In a very short time, the Covid-19 epidemic has affected all economic sectors, of which the tourism industry is heavily affected. According to statistics over the past 3-4 years, Vietnam's tourism has witnessed a spectacular growth of the highest in the world with an average of over $20 \%$ per year. Specifically, in 2019 Vietnam welcomed a record high number of international visitors of more than 18 million and has set a target of welcoming about 20.5 million in 2020. The Covid-19 epidemic is actually a shock to Vietnam's tourism industry in the early days of 2020. Since January 28, 2020, the Chinese government has banned all domestic tourism activities and foreign tourism and seriously affect the countries that welcome many Chinese tourists such as Southeast Asia, Korea, Japan, etc. In this context, what actions should leaders take and which leadership style will be effective for business as well as the impact of leadership style on supply chain quality management in Vietnam's tourism industry? This study aims to examine the relationship between transaction leaders, supply chain quality management (SCQM) and business performance in tourism Vietnam. Effective SCQM is a tool to improve competitive advantage and improve business performance (Suhong et al., 2006). However, SCQM depends heavily on the characteristics of leaders and managers who are authorized to make decisions and operate businesses. Facing the economic recession of the Covid - 19 pandemic, as well as the fierce global competitive trend, leaders are required to have effective methods and styles (Cruz \& Wang, 2018). Leaders play an essential role in managing the quality of the supply chain, especially in the field of tourism and travel. There are presently many different leadership styles such as conversion leadership, transaction, distribution, civil servants or other supporting leadership functions. Due to the peculiarities of Vietnamese human culture, and the context of Vietnam's tourism and travel businesses, we focus on transactional leadership - an available leadership style.

\footnotetext{
* Corresponding author Tel. : +84 0914915926

E-mail address: hien.aasc@gmail.com (T.T.H. Phan)

(C) 2020 by the authors; licensee Growing Science. doi: $10.5267 /$ j.uscm.2020.7.002
} 
The layout of the article in addition to the introduction includes: Research overview, research methods, research results and conclusions.

\section{Literature review}

\subsection{Transactional leadership}

Leadership characteristics will lead to different leadership styles, which form the two typical leadership styles: transactional leadership and transformational leadership (Bass, 1985; Burns, 1978). The style of trading leadership is consistent with the context in which leaders promote employee compliance with the overall goals of the business through clear rewards and broadcasts (Kuhnert \& Lewis, 1987). Trading leaders are based on the premise that employees are motivated by a system of penalties and rewards. Employees are assigned clear, specific tasks and expect to perform tasks exactly as agreed. Employees complete tasks as assigned resulting in rewards and increase performance success. The rewards may be material (such as increased employment security (promotion opportunities), bonuses or other awards). Intangible rewards are also used by trading leaders. These rewards may include positive feedback, recognition and praise. Failure to perform assigned tasks may produce negative feedback in a state of frustration, dissatisfaction and disapproval, and may result in disciplinary action or material penalties. Trading leaders are useful when the company's operations require that the work be done exactly as prescribed (Yukl, 2013). According to Yukl (2013), transaction leadership is made up of 4 aspects: rewards, managing by expectations (being proactive), managing by expectations (being passive) and ultimately avoiding being passive. The reward is the goal as a result of the action process and will motivate employees to strive, strive hard to pursue the goal and fulfill the responsibilities under the signed labor contract / economic contract (Camps \& Torres, 2010). Expected (exceptions) management actively refers to compliance, proactively motivates employees under the direction of management to ensure compliance with regulations, goals and standards of businesses (Penno, 2017). Expected (passive) management means that managers only intervene when employees, the operating system do not comply with the rules and regulations set out or incidents or errors occur in operations. business of the business. A very important aspect is the avoidance of passive, demonstrating the management of leaders to minimize the passivity and lumbering of the employees' system in production and business activities of the enterprise (Chaudhry \& Javed 2007).

The trading leadership style always motivates employees and people in the system to actively and seriously implement organizational goals including important areas such as innovation and creativity to achieve business efficiency (Antonakis \& House, 2014). Trading leaders have a positive impact on labor productivity, the efficiency of the operations, divisions in the business thereby contributing to improving the business performance of the business (Bass et al., 2003).

According to two different anthropological theories: Theory X (people are inherently lazy, need to track, test, and make commitments by "stick" or "carrot"); Theory Y (People are not lazy, they are just lazy because they are not supported by beliefs, values, or other spiritual values. Once they have the right motivation, they will return to their nature. mine). Trading leaders have a different "customer base", they believe in theory X. So, they focus on specific activities. Define tasks and assign tasks with a strict control system. Work-focused work is the goal of this style. They value material punishment, because they believe human loyalty is the loyalty of a "cat"; loyalty to its food.

\subsection{Supply chain management, supply chain quality}

Supply chain management or management is used to describe the need to link all major business processes, from the end user to the first supplier. Initially managing the supply chain was only the transportation and logistics activities associated with purchasing goods. Gradually, this process soon expanded to the distribution area as well as logistics for end consumer customers. Through this activity, companies as well as businesses unite them in a supply chain by exchanging information on market fluctuations and production capacity. SCM's supply chain management plays an important role for manufacturing and construction businesses, especially tourism businesses in the context of economic hardship affected by the Covid epidemic - 19 diaphragm. In addition, the market competition is getting higher, the selling price and purchasing price are also strictly controlled. Supply chain management (SCM) has a great impact on customer trust, market dominance, and the ability to reach out of the business. Supply chain is also one of the determinants of a company's competitiveness compared to competitors in the same industry. Large corporations such as Wal-Mart or Dell have made a significant amount of profit compared to competitors. In addition, effective supply chain management also brings benefits such as: Reducing costs for the supply chain by $25-50 \%$, reducing inventory by $25-60 \%$, increasing accuracy in production forecasts from $25 \%$ to $80 \%$, improving supply chain orders by $30-50 \%$ and increasing profit after tax by about $20 \%$ (Phan et al., 2019). Supply Chain Quality (SCQ) is a way to coordinate the leadership, operation and implementation of activities in the supply chain to ensure the duties and responsibilities of the components in the supply chain. flexibility and efficiency (Lin et al., 2013).

\subsection{Supply Chain quality management (SCQM)}

As the competition moves beyond a company's internal scope and emphasizes the company's supply network, the focus is shifting from internal practice management to corporate governance and external partner. Quality managers must integrate business practices (inside the business such as quality design, process management, continuous improvement) of the business with the activities of customers and suppliers. Integrating the two concepts of quality management and supply chain management is an inevitable trend that determines the future competitiveness of the supply chain. Supply Chain 
Quality Management (SCQM) is a concept that was born from the idea in the 2000s. SCQM is the synergistic effect between supply chain management (SCM) and quality management (QM). This approach assumes that the traditional approach to SCM is no longer appropriate and proves less effective in the current competitive context, applying the QM principles to open up new opportunities to improve operating results the chain (Flynn \& Flynn, 2005). Using this approach SCQM is: formal coordination and integration of business processes involving all partner organizations in the supply channel to measure, analyze and continually improve products, services and processes to create value and achieve intermediate and final customer satisfaction in the marketplace (Robbins et al., 2007). The two authors described the SCQM system of traditional quality management activities, focusing on the internal supply chain with practice activities within the organization and cooperative activities, integrating the Supply chain staff focuses on the external supply chain with interorganizational practices. According to Foster (2008) SCQM is a system-based approach to improving performance using opportunities created by downstream and upstream links with suppliers and customers (Foster, 2008).

\subsection{Performance}

According to Smith and Reece (1999), business performance is the operational capacity of a company to meet shareholders' expectations, which means that it is primarily in the direction of maximizing profits and dividends for shareholders. of the company. However, according to Zulkiffli and Perera (2011), business performance needs to be assessed, measured and analyzed by evaluating and comparing actual performance with the company's goals and expectations, these activities include both strategic orientation and specific production and business activities. Business performance can be measured either by subjective methods based on CEO's comments on performance indicators or measured by objective methods based on public financial indicators such as stock prices. votes, the profitability performance of assets, the profitability performance of equity, capital growth, profitability ... These indicators can also be evaluated based on subjective judgment of leaders compared to industry expectations or to industry averages of businesses in the same industry (Aljena 2017; Mikelsone \& Liela, 2016; Le et al., 2019). When measuring the performance of enterprises, Kaplan and Norton (1992) think that it is necessary to maintain a balance between financial and non-financial measures, thereby developing a balanced scorecard (BSC) and classification of brands. Business results into four measures, namely financial performance, customer satisfaction, internal business processes and innovation and academic perspectives. In this study, we believe that supply chain quality management does not simply affect financial efficiency. Financial efficiency is only the figures that are published in financial reports, supply chain quality management also has a strong impact on non-financial efficiency. Therefore, we measure business performance in both financial and non-financial aspects developed from the research of Phan et al. (2019) and Le et al. (2019).

\subsection{Supply chain quality management and performance}

Improving organizational performance is the goal of all governance efforts. Performance is the level of accomplishment of the set goals. Performance is a very important parameter for effective governance of any organization. The success of an organization / supply chain is basically explained by its performance over a period of time. Focusing on integration of supply chain quality and supply chain quality management will enhance the performance of your business (Huo et al., 2019). The impact of supply chain quality management on performance has been well studied, but the relationship between supply chain quality management and performance is still conflicting (Fish, 2011). According to Uwamahoro (2018), the degree of integration of supply chain quality management changes leads to a change in operational efficiency. Better quality management of the supply chain leads to superior productivity and quality of service delivery, thus positively impacting business performance and flexibly responding to customer requirements. Integrating supply chain quality management and effective supply chain management combined with transaction leadership will help companies gain a competitive edge and thereby positively impact on performance in both financial and non-financial aspects (Yu \& Huo, 2018).

\section{Research Methodology}

\subsection{Context and research sample}

From the perspective of an economic sector, tourism is a comprehensive business that brings high efficiency in many aspects: improving knowledge about nature, historical traditions, national culture, thereby contributing to increasing more country love. Besides, tourism is also considered a form of exporting goods and services on the spot, bringing huge economic efficiency. In recent years, Vietnam tourism is on a strong development, the number of international and domestic tourists is increasing. Vietnam tourism is increasingly expanding and known more in the world, many domestic destinations are voted as favorite addresses of international visitors. According to the statistics of the Vietnam National Administration of Tourism, in the first 9 months of 2019, the General Department of Tourism (Ministry of Culture, Sports and Tourism) said that the number of international visitors to Vietnam was estimated. nearly 9.8 million arrivals, an increase of $7.9 \%$ compared to the same period in 2018 (excluding domestic tourists). In particular, the number of passengers coming by air reached more than 7.7 million (up 4.7\% compared to the same period in 2018); arrivals by sea reached 158 thousand (down $11.3 \%$ over the same period in 2018); arrivals by road reached nearly 2 million (up $25.2 \%$ over the same period in 2018 ). The number of domestic tourists in 2019 reached nearly 60 million, of which 26.9 million stayed. The total revenue from tourists reached 401 trillion VND, up 8.67\% over the same period in 2018 . 
Along with that, the national tourism image is increasingly enhanced. The system of world cultural and natural heritage of Vietnam recognized by UNESCO is increasingly rich, such as Ha Long Bay, Phong Nha - Ke Bang National Park, Trang An Landscape Complex, Hoi An Ancient Town, Ancient Ruins of Hue Monuments and Dong Van Rock Plateau. In addition, the tourism industry is also contributing to creating jobs and settling social security for millions of Vietnamese people. By 2019 , over 2 million people are estimated to work in the tourism sector. In 2019, Vietnam has more than 2,000 international travel businesses including nearly 16,000 international guides and over 8,700 domestic guides. The total number of tourist accommodation establishments in the country is 29,000 accommodation establishments with over 590,000 accommodations, including 146 5-star hotels, 280 4-star hotels; 13 5-star tourist apartments; 4 4-star travel apartments. In order to accomplish the research objective, we have sent the survey questionnaire to senior and mid-level leaders in tourism and travel businesses who have been recognized as typical tourism businesses according to the ranking of Total Vietnam Tourism Department (2019). We sent all 500 questionnaires to these businesses within 3 months and collected 326 votes, after cleaning the remaining 298 valid surveys to be analyzed.

\subsection{Research models}

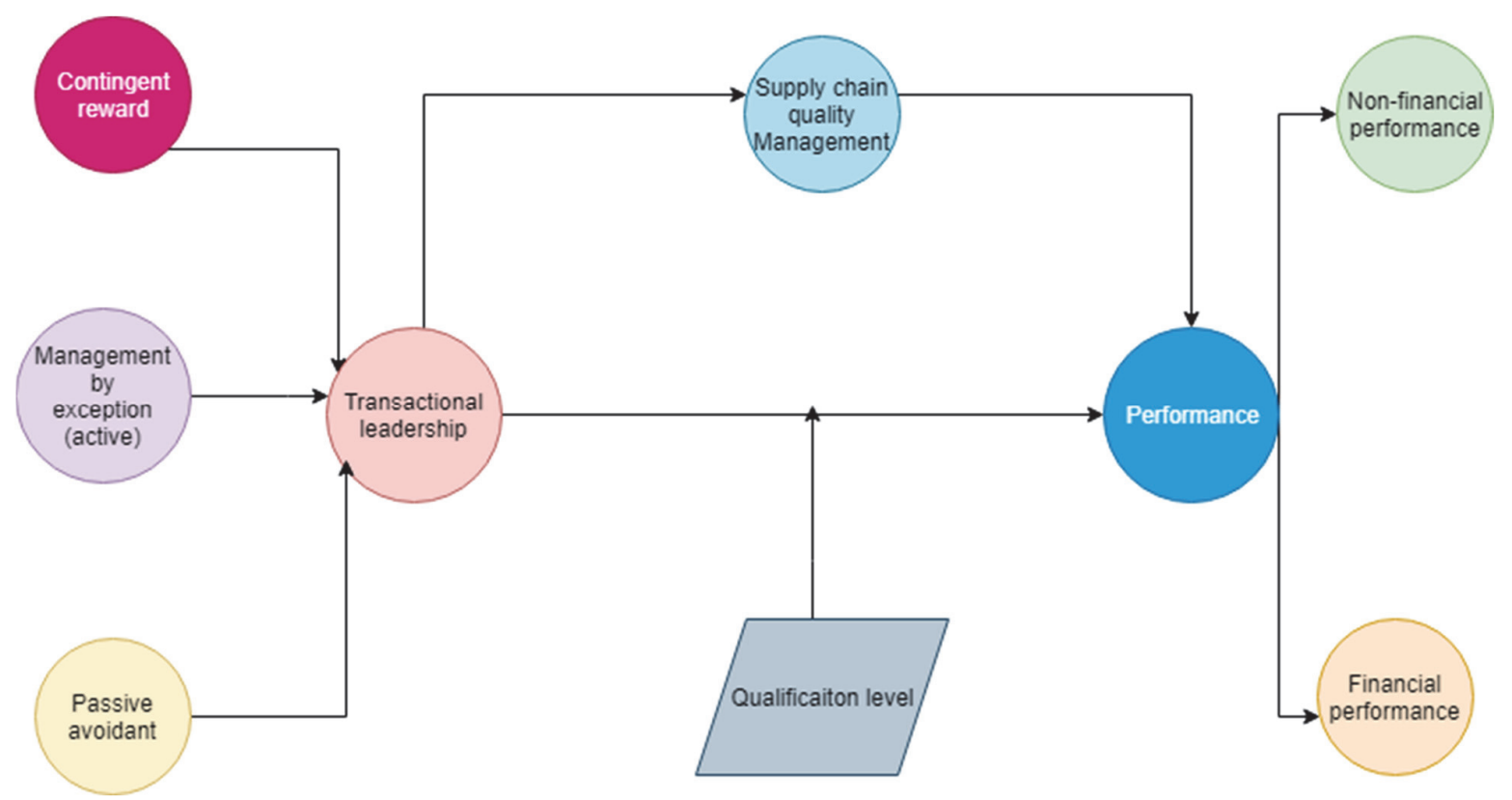

Fig. 1. Research models

In the research model, the research variables in the model are described as follows:

Transactional leadership: Including 3 dimensions: Contingent Reward, Management by exception (active) and Passive avoidant measured by a scale of Likert from 1 - not at all, to 5 - frequently. Includes 9 items developed from research by Penno (2017) and Jacobs \& Mafini (2019). The scales for Transactional leadership are as follows:

Re-examine critical assumptions to question whether they are appropriate in tourism

Make clear what one can expect to receive when performance goals are achieved in tourism

Discuss in specific terms in tourism who is responsible for achieving performance targets

Avoid making decisions

Am absent when needed

Avoid getting involved when important issues arise

Direct my attention towards failures to meet standards

Keep track of all mistakes

Concentrate my full attention on dealing with mistakes, complaints and failures

Supply chain quality management: Measured by 8 items developed from Teoman \& Ulengin (2017) as measured by a 5point likert scale of 1 for strongly disagree to 5 for agree strongly. The specific scales of the research variable are as follows:

Top management commitment to quality in the tourism supply chain 
Focus on human resources in the tourism supply chain

Overall participation and teamwork in the tourism supply chain

Customer focus in tourism supply chain

Commitment to continuous improvement in the tourism supply chain

Cooperative relationships with SC partners in the tourism supply chain

Suppliers and logistics partners quality management in the tourism supply chain

Focus on sustainability and environment in the tourism supply chain

Performance: Measured by 7 items developed by Phan et al. (2019), Le et al. (2019) and Jacobs \& Mafini (2019). The scales are compared to the industry average of the last 3 years with a 5 point likert scale from 1 which is much lower to 5 much higher. The specific scales are as follows:

Customer satisfaction

Productivity

Supplier performance

Employee satisfaction

Cost savings

Sales or revenue growth

Profitability

The research hypotheses of the research model are as follows:

$\mathrm{H}_{1}$ : Transactional leadership has a positive impact on supply chain quality management in tourism and travel enterprises in Vietnam

$\mathrm{H}_{2}$ : Supply chain quality management has a positive impact on Performance in tourism and travel enterprises in Vietnam

$\mathrm{H}_{3}$ : Transactional leadership has a positive impact on Performance in tourism and travel enterprises in Vietnam

$\mathrm{H}_{4}$ : Supply chain quality management plays a mediate role in the relationship between transactional leadership and Performance in tourism and travel enterprises in Vietnam.

$\mathrm{H}_{5}$ : Qualification level has a moderate role in the relationship between transactional leadership and Performance in tourism and travel enterprises in Vietnam.

\subsection{Methods of analysis}

To analyze the research data, we used 2 analysis software, SPSS 22 and Smart PLS 3.0.

We first conducted a reliability test of the scale using Cronbach's Alpha coefficient and total correlation. The Cronbach's Alpha coefficient has a variable value in the segment [0,1]. In theory, the higher the coefficient, the better (the more reliable the scale). However, this is not entirely accurate because Cronbach's Alpha coefficients are too large (about 0.95 and above) to show that many observed variables in the scale do not differ, they are almost completely the same. This phenomenon is called duplication in the scale (Hair et al. 2011, 2014, 2017; Henseler et al. 2009; 2015). If a variable has a correlation coefficient of Corrected Item - Total Correlation $\geq 0.3$, that variable is satisfactory (Hair et al. 2011, 2014, 2017; Henseler et al. 2009; 2015). Corrected Item - Total Correlation coefficient indicates the correlation between that observed variable and the remaining variables in the scale, if the observed variable has a stronger correlation with the variables in the group. Thus, when performing Cronbach's Alpha reliability test, the observed variable has a total correlation coefficient less than 0.3 , we need to run again for the second time. Cronbach's Alpha coefficient value levels have the following meanings,

From 0.8 to close to 1 : very good measurement.

From 0.7 to nearly 0.8 : good measurement scale.

From 0.6 and above: eligible measurement scale (Henseler et al. 2009, 2015).

Next, we conducted an EFA discovery factor test on SPSS 22 assessed using KMO and Sig coefficients. 
Finally, we evaluate the general reliability value, discriminant validity, evaluate measurement models, structural models and test research hypotheses with Smart PLS 3.0 using PLS and Bootstrap techniques.

\section{Research results}

The implementation of the reliability test of scales were performed on SPSS 22 software, the results have shown that all scales of the latent variables had a Cronbach's Alpha value greater than 0.7 and a larger correlation value of 0.3 satisfies the reliability conditions suggested by Hair et al. $(2011,2013)$ and Henseler et al. $(2009,2015)$. Except for the three scales of the potential supply chain quality management variable (SCQM) namely SCQM2, SCQM4 and SCQM7 which have a correlation coefficient of variable of smaller than 0.3 and Cronbach Alpha value less than 0.6. Therefore, we have removed those 3 scales from the research data. After removing 3 scales SCQM2, SCQM4 and SCQM7, we ran again to test the reliability and value of the scales in the latent variables, which all satisfy the condition that the value of Cronbach Alpha is greater than 0.7 and the coefficient of correlation. The total variable is greater than 0.4 . Therefore, all scales satisfy the next analytical condition. We continue to conduct an analysis of the EFA discovery factor, the results show that the variables constituting the transaction leadership style have been separated into 3 separate factors with a coefficient of KM0 $=0.832$ greater than 0.5 with Sig. $=0.000$, thus satisfying the condition (Hair et al., 2011, 2014; Henseler et al., 2009, 2015). Similarly, two aspects of operational efficiency, financial efficiency and non-financial efficiency, are also extracted into two separate factors with coefficient $\mathrm{KMO}=0.803$, Sig. $=0.000$. The latent variable SCQM runs agglomeration into a factor with $\mathrm{KMO}=0.856$, Sig. $=0.000$. Thus, all factors are satisfied to continue the next analysis steps. Next with the data removed the scales when they did not meet the reliability and value conditions, we conducted data analysis on Smart PLS 3.0 software with the following results:

Table 1

Construct Reliability and Validity

\begin{tabular}{lcccc}
\hline & Cronbach's Alpha & rho_A & Composite Reliability & Average Variance Extracted (AVE) \\
\hline Contingent reward & 0.910 & 0.911 & 0.930 & 0.991 \\
Financial performance & 0.867 & 0.874 & 0.904 & 0.654 \\
Management by exception active & 0.911 & 0.911 & 0.934 & 0.737 \\
Non-Financial performance & 0.916 & 0.917 & 0.922 & 0.749 \\
Passive avoidant & 0.872 & 0.873 & 0.955 & 0.797 \\
Performance & 0.947 & 0.950 & 0.940 & 0.682 \\
Supply chain quality management & 0.920 & 0.920 & 0.968 & 0.758 \\
Transactional leadership & 0.964 & 0.965 & & 0.685 \\
\hline
\end{tabular}

Looking at Table 1 shows, all the study variables have a large overall Cronbach Alpha coefficient of 0.9 which proves a very good measurement scale. All aggregate reliability factors are greater than 0.7 and AVE are greater than 0.5 . Thus, according to Henseler et al. $(2009,2015)$ the scales of the study variables satisfy the conditions of value and reliability to perform the next analysis.

Table 2

Discriminant Validity (Fornell-Larcker Criterion)

\begin{tabular}{|c|c|c|c|c|c|c|c|c|}
\hline & 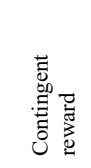 & 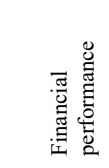 & 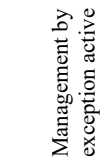 & 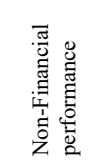 & 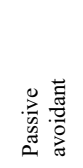 & 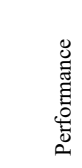 & 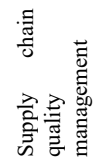 & 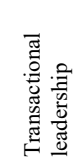 \\
\hline Contingent reward & 0.831 & & & & & & & \\
\hline Financial performance & 0.312 & 0.809 & & & & & & \\
\hline Management by exception active & 0.129 & 0.317 & 0.859 & & & & & \\
\hline Non-Financial performance & 0.285 & 0.145 & 0.286 & 0.866 & & & & \\
\hline Passive avoidant & 0.285 & 0.292 & 0.182 & 0.268 & 0.893 & & & \\
\hline Performance & 0.302 & 0.284 & 0.305 & 0.188 & 0.283 & 0.826 & & \\
\hline Supply chain quality management & 0.434 & 0.490 & 0.412 & 0.499 & 0.445 & 0.502 & 0.870 & \\
\hline Transactional leadership & 0.279 & 0.319 & 0.275 & 0.291 & 0.240 & 0.309 & 0.443 & 0.827 \\
\hline
\end{tabular}

Looking at Table 2 shows that all values outside the diagonal are smaller than the values on the diagonal of the discriminant value table. The maximum value outside the diagonal of 0.502 is still smaller than the smallest value on the diagonal of 0.809 , which means that the research data ensures the discriminant validity, eligible for the next analysis.

Table 3

The results of R-Square

\begin{tabular}{lll}
\hline & R Square & R Square Adjusted \\
\hline Performance & 0.352 & 0.350 \\
Supply chain quality management & 0.296 & 0.294 \\
\hline
\end{tabular}


The results show that the variables in the research model explain more than $35 \%$ of the variability of the performance of tourism and tourism businesses in Vietnam. It is also an interesting result, because we only focus on studying two factors: transactional leadership and supply chain quality management, but the level of explanation has reached more than $1 / 3$ of the performance of the business.

Table 4

The results of F-value

\begin{tabular}{|c|c|c|c|c|c|c|c|}
\hline 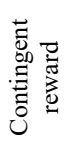 & 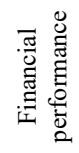 & 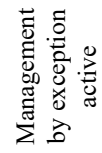 & 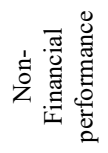 & 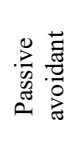 & 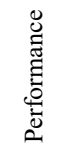 & 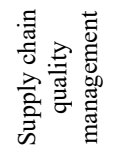 & 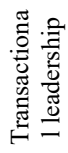 \\
\hline & & & & & & & 0.254 \\
\hline & & & & & & & 0.265 \\
\hline & & & & & & & 0.261 \\
\hline & \multirow[t]{3}{*}{0.329} & & 0.318 & & & & \\
\hline & & & & & 0.337 & & \\
\hline & & & & & & 0.244 & \\
\hline
\end{tabular}

$\mathrm{f} 2=\left(\mathrm{R} 2 \_\right.$included $-\mathrm{R} 2 \_$excluded $) /(1-\mathrm{R} 2$ included $)$

where R2_included and R2_excluded are the R-squared values of the endogenous variables when the corresponding exogenous variables are included in the model or removed from the model. This means that R2 value is calculated by PLS twice, first with full potential exogenous variables (giving R2_included results) and second with exogenous variables not in the model (giving values R2_excluded). The values of $f 2$ correspond to $0.02,0.15$, and 0.35 , corresponding to the small, medium and large impact values (Henseler et al. 2009) of exogenous variables. If the effect size is $<0.02$, it is considered as having no effect. Looking at the results in the figure, the research variables are interplayed above average.

Table 5

Model_Fit (Fit Summary)

\begin{tabular}{lll}
\hline & Saturated Model & Estimated Model \\
\hline SRMR & 0.056 & 0.058 \\
d_ULS & 0.953 & 0.982 \\
d_G & 0.472 & 0.4 .89 \\
Chi-Square & $1,635.658$ & $1,688.286$ \\
NFI & 0.886 & 0.889 \\
\hline
\end{tabular}

The data in the above table shows that the research model is consistent with the research data.

Table 6

Path Coefficients

\begin{tabular}{|c|c|c|c|c|c|c|c|}
\hline \multirow[b]{2}{*}{ 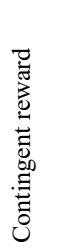 } & \multicolumn{4}{|c|}{$\vec{b}$} & \\
\hline & 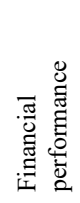 & 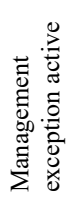 & 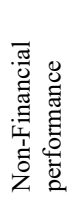 & 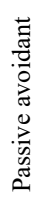 & 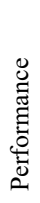 & 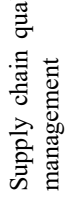 & 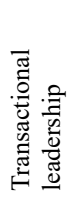 \\
\hline
\end{tabular}

Contingent reward

Financial performance

Management by exception active

0.374

Non-Financial performance

Passive avoidant

Performance

0.984

0.988

Supply chain quality management

0.502

Transactional leadership 
With the above results, we conducted research hypotheses by bootstrap technique on Smart PLS 3.0 with the following results:

Step 1 we test the direct impact of trading leadership style on performance with the following results:

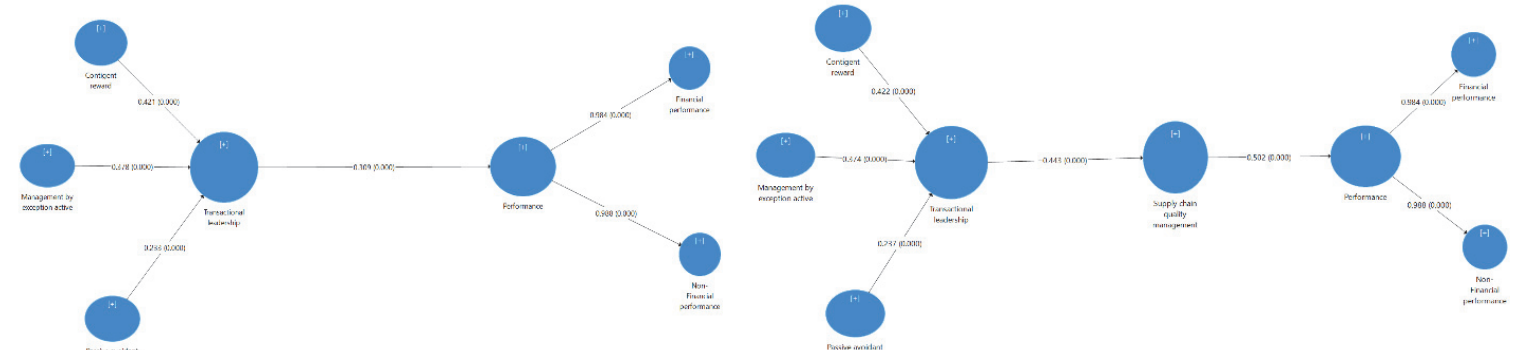

Fig. 2. Results of direct impact of trading leadership style on performance
Fig. 3. The bootstrap test result without considering the intermediary role

From the above results (Fig. 2), all three constituent aspects of trading leadership are satisfied and statistically significant with $\mathrm{P}$ value value of 0.000 . In addition, business performance is reflected in two aspects: financial efficiency and nonfinancial efficiency, and all are at Sig value. $=0.000$. Therefore, all research variables satisfy the problem. Once the underlying variables have satisfied the condition, we test the direct impact of trading leadership on performance with a very strong impact of 0.309 (Hair et al., 2014, 2017) with 1\% $\left(\mathrm{P}_{-}\right.$value $\left.=0.000\right)$. As such, it is eligible to carry out the next audit to test the intermediary role of supply chain quality management in the relationship between transaction leadership and performance.

Step 2, we examine the impact of transaction leadership style on supply chain quality management and supply chain quality management on the performance of software extracted results using bootstrap technology as follows:

From the results given in Fig. 3, the transaction leadership style has a strong impact on the quality management of supply chains in Vietnam's tourism businesses with an impact of 0.443 at $1 \%$ significance level $(\mathrm{P}$ value $=0.000)$. Continued quality management of the supply chain also has a strong impact on performance with an impact of up to 0.502 at $1 \%$ significance level $(\mathrm{P}$ value $=0.000)$. With the cultural characteristics of Vietnam, employees always tend to listen to the leadership and comply with the rules and regulations of the business sometimes a little rigid. However, in the context of the heavily affected tourism industry by the covid -19 epidemic, the transaction leadership style exerts a great effect on supply chain quality management. By this time, the subsidiaries of large corporations, or branches, brand restaurants must comply with the provisions of the state as well as the parent company. Therefore, in this case, the transaction leadership style helps to improve the quality of the supply chain of tourism and tourism in Vietnam. When the quality of the supply chain is effectively managed, it will create trust for customers, build brands for businesses in the context of the general crisis of the world and Vietnam. This will help tourism and travel businesses improve operational efficiency in both financial and nonfinancial aspects. When the quality of the supply chain is guaranteed, it means that the operations of businesses are not tied up, not suspended, so employees are still guaranteed the work, income and wages so they do more effective, a better business reputation and more satisfied and loyal customers. Thereby leading to increased sales, increased profits, indicators of stock (if any) increased and improved financial efficiency.

Step 3 after pairs of hypotheses act individually are statistically significant, thus, according to Hair et al. (2014) satisfies the conditions for testing the intermediary role of supply chain quality management in the relationship between transaction leadership and the performance of tourism service enterprises. and travel in Vietnam.

The bootstrap results in the overall SEM model are as follows:

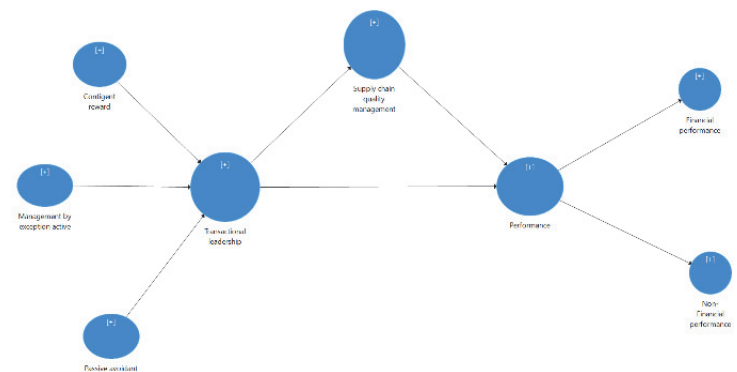

Fig. 4. Model of testing the mediate role of supply chain quality management

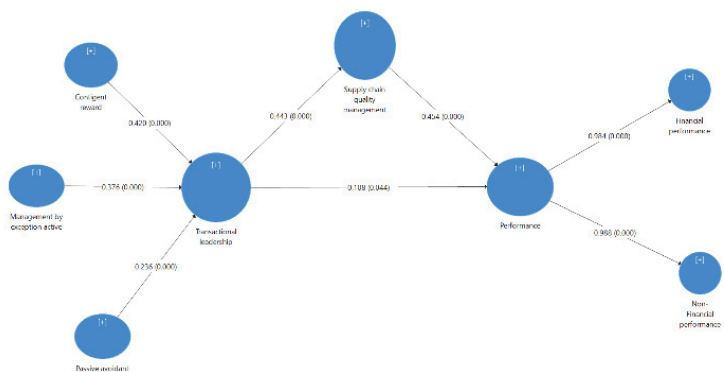

Fig. 5. Results of testing the mediate role of supply chain quality management 
The results in Fig. 5 show that, in the overall SEM model, the trading leadership style no longer has a statistically significant impact on the performance of the $1 \%$ significance level. However, at the 5\% significance level, transaction leadership still has a statistically significant impact on performance. Therefore, supply chain quality management does not have a full intermediary role in the relationship between transaction leadership style and performance, but only a partial intermediary relationship in this relationship.

Next, we examine the regulatory role of qualification in the relationship between trading leadership style and performance. The testing model and results are as follows:

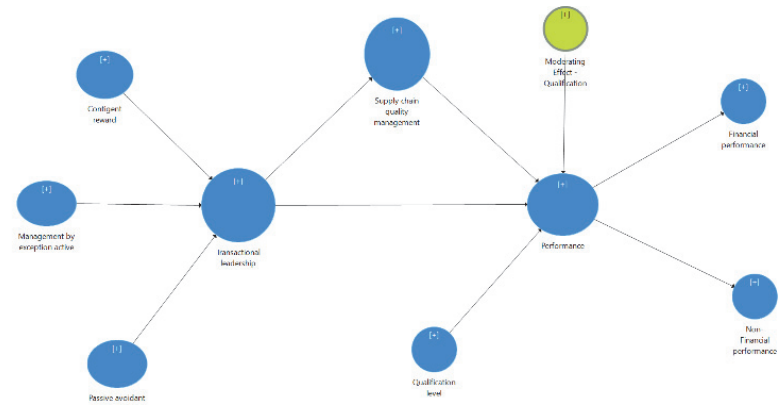

Fig. 6. Model of testing the moderate role of leadership qualification

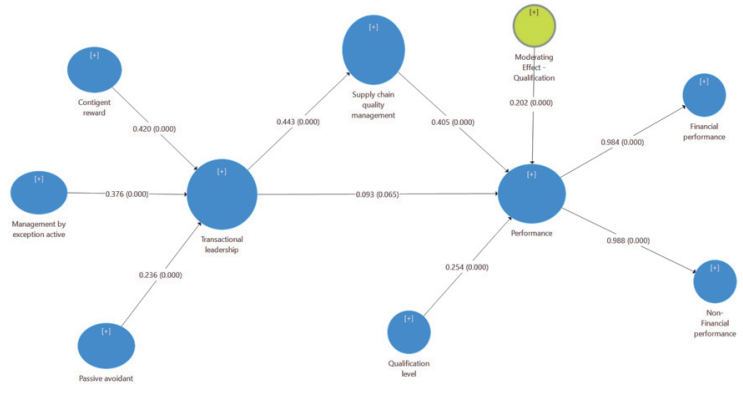

Fig. 7. Results of testing the moderate role of a qualification level

From the results in Fig. 7, the level of leadership expertise has a strong impact on performance (Hair et al., 2017) at the impact level of 0.254 at the $1 \%$ significance level $(\mathrm{P}$ _value $=0.000)$, which means qualifying for the moderator role. From the above results, it is shown that the moderator of the qualifications of the leadership also has a strong positive impact on the performance of the impact level of 0.202 at the $1 \%$ significance level $\left(\mathrm{P}_{-}\right.$value $\left.=0.000\right)$. In order to visualize the regulatory impact of the leadership's qualification, we conduct the following graphical analysis:

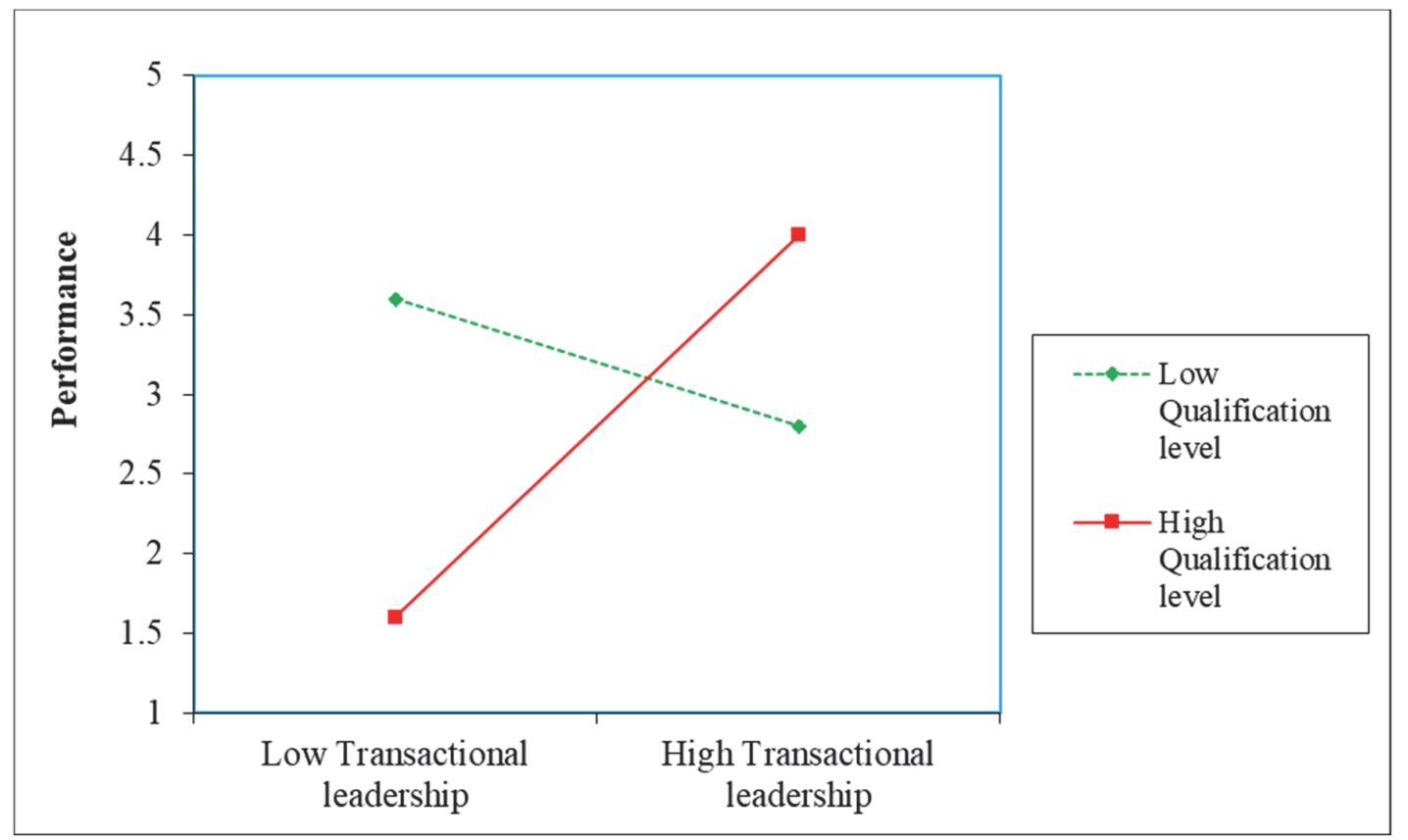

Fig. 8. The moderate role of qualification level

According to Fig. 8, leaders with the high trading style combined with high professional qualifications will make the performance of businesses increase dramatically. In fact, the world has proved that for example Bill Gate is also a trading leader and he was very successful. In Vietnam, especially in the field of tourism and travel services, the better the leader, the more highly qualified the leadership of the transaction will better help the business performance of businesses. In addition, the lower the professional level, the more applied the trading leadership style makes the business efficiency go down. Because, the style of transaction leadership requires leaders to have a vision, to have the right strategy, otherwise employees will not have creativity, not the right direction, the business is underperforming is the inevitable.

Finally, we summarize the results of testing the relationships, the effects between the study variables in Table 7 as follows: 
Table 7

Path Coefficients (Mean, STDEV, T-Values, P-Values)

\begin{tabular}{|c|c|c|c|c|c|}
\hline & 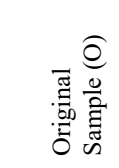 & 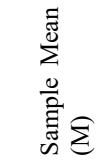 & 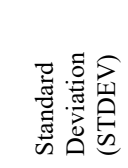 & 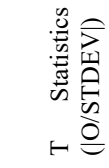 & $\frac{\stackrel{\mathscr{d}}{\Xi}}{\frac{\pi}{\pi}}$ \\
\hline Contingent reward $\rightarrow$ Transactional leadership & 0.420 & 0.421 & 0.007 & 61.971 & 0.000 \\
\hline Management by exception active $\rightarrow$ Transactional leadership & 0.376 & 0.375 & 0.008 & 44.778 & 0.000 \\
\hline Passive avoidant $\rightarrow$ Transactional leadership & 0.236 & 0.236 & 0.007 & 32.196 & 0.000 \\
\hline Performance $\rightarrow$ Financial performance & 0.984 & 0.984 & 0.002 & 493.497 & 0.000 \\
\hline Performance $\rightarrow$ Non-Financial performance & 0.988 & 0.988 & 0.001 & 709.331 & 0.000 \\
\hline Supply chain quality management $\rightarrow$ Performance & 0.454 & 0.453 & 0.045 & 10.007 & 0.000 \\
\hline Transactional leadership $\rightarrow$ Performance & 0.108 & 0.109 & 0.054 & 2.016 & 0.044 \\
\hline
\end{tabular}

Table 8

Confidence Intervals Bias Corrected

\begin{tabular}{|c|c|c|c|c|c|}
\hline & Original Sample $(\mathrm{O})$ & Sample Mean (M) & Bias & $2.5 \%$ & $97.5 \%$ \\
\hline Contingent reward $\rightarrow$ Transactional leadership & 0.420 & 0.421 & 0.001 & 0.405 & 0.432 \\
\hline Management by exception active $\rightarrow$ Transactional leadership & 0.376 & 0.375 & -0.001 & 0.362 & 0.396 \\
\hline Passive avoidant $\rightarrow$ Transactional leadership & 0.236 & 0.236 & 0.000 & 0.224 & 0.252 \\
\hline Performance $\rightarrow$ Financial performance & 0.984 & 0.984 & 0.000 & 0.980 & 0.987 \\
\hline Performance $\rightarrow$ Non-Financial performance & 0.988 & 0.988 & 0.000 & 0.984 & 0.990 \\
\hline Supply chain quality management $\rightarrow$ Performance & 0.454 & 0.453 & -0.001 & 0.358 & 0.540 \\
\hline Transactional leadership $\rightarrow$ Performance & 0.108 & 0.109 & 0.000 & -0.004 & 0.205 \\
\hline Transactional leadership $\rightarrow$ Supply chain quality management & 0.443 & 0.443 & 0.000 & 0.352 & 0.515 \\
\hline
\end{tabular}

Looking at Table 8 shows, all bias, errors are controlled, research models are consistent with the research data and ensure the reliability and value of the scales and models research.

\section{Conclusions}

Facing complicated movements of the epidemic, Vietnam is losing a big market, China. Therefore, the tourism industry needs a new direction, identifying the domestic market as the top priority. At the same time, it is possible to consider new destinations, which are not epidemic or unable to relapse such as: USA, Australia, Canada, etc. Besides, to create the attraction of domestic tourism, it is necessary to have a comprehensive solution from organizing activities to stimulate domestic tourism and organize service providers to form package tourism programs at preferential prices for Vietnamese tourists. It is necessary to invest in new domestic tourist routes, focusing on exploiting community-based ecotourism and tourism in association with environmental protection. Tourism companies also need to study changes in crisis market orientation, with the focus from the Chinese market showing that it is almost too much reliance on one or two major markets for Vietnam's tourism. 1/3 of total international visitors to Vietnam, China and South Korea account for over half of the total number of international visitors to Vietnam. When the epidemic is over, the Chinese market will need more time to recover. Vietnam tourism businesses need to research to attract other potential target markets. From these difficulties, Vietnam can also be seen as an opportunity to look back on itself and prepare for the future, in introducing new and varied products, developing a direct and in-depth image promotion strategy, expanding to the world as well as affirming more and more since Vietnam is one of the potential and rich countries of Asia. If so, then we can see the talent of the captain. Leaders must grasp the situation and make the right decisions appropriate to the time with their businesses. Moreover, in the current context, leaders always have to improve their professional skills and knowledge to apply effective trading leadership. Tourism companies need to unite with aviation, transportation, hotels, restaurants, etc. to build tourist stimulus packages to help tourism recover quickly after the crisis. Businesses can organize to invite partners, large customers to attend FAM trips to introduce products

In terms of the state, the management agencies can play the role of conductor to connect the tourism, aviation, hotels, restaurants, transportation, entertainment areas, etc. with discount to get to have the tour stimulus package. In addition, the State should also exempt visa fees for key, potential and high-paying markets to attract customers from these markets. At the same time, there are tax exemption and reduction policies for businesses in the tourism industry. During and after the pandemic, the government should have policies to support and offset the tourism industry. When tourism is a spearhead 
economic sector, not only epidemics, but also guest crises related to terrorism, political conflicts, economic recession, natural disasters, etc. will all be greatly affected. If tourism businesses do not accompany and respond right from the crisis, they will limit the ability to recover and welcome the future of their own businesses.

\section{Acknowledgement}

This research is funded by National Economics University, Hanoi, Vietnam.

\section{References}

Aljena, A. (2017). Value proposition management in the contemporary fine art: Case studies of six Latvian artists. Journal of Business Management, 17(12), 46-61.

Antonakis, J. \& House, R.J. (2014). Instrumental leadership: Measurement and extension of transformational-transactional leadership theory. The Leadership Quarterly 25(4), 746-771.

Bass, B.M., (1985), Leadership and performance beyond expectations, Free Press, New York

Bass, B.M., Avolio, B.J., Jung, D.I. \& Berson, Y., (2003). Predicting unit performance by assessing transformational and transactional leadership. Journal of Applied Psychology 88(2), 207-218.

Burns, J.M., (1978). Leadership, Harper \& Row, New York

Camps, J. \& Torres, F., (2010). Contingent reward leader behaviour: Where does it come from? Systems Research and Behavioral Science, 28(3), 212-230.

Chaudhry, A.Q. \& Javed, H., (2007). Impact of transactional and laissez-faire leadership style on motivation. International Journal of Business and Social Science, 3(7), 258-264.

Cruz, J. \& Wang, H., (2018). Transformational leadership in supply chain management, viewed 28 April 2018.

Foster, Jr. S.T., (2008). Towards an understanding of supply chain quality management. Journal of Operations Management, 26(4), 461-467.

Flynn, B. B., \& Flynn, E. J. (2005). Synergies between supply chain management and quality management: Emerging implications. International Journal of Production Research, 43, 3421- 3436.

Fish, L.A., (2011). Supply chain quality management, in D. Onkal (ed.), Supply chain quality management, supply chain management - Pathways for research, p. 26, In Tech Open, London.

Hair, J.F., Ringle, C.M. and Sarstedt, M. (2011). PLS-SEM: in deed a silver bullet, Journal of Marketing Theory and Practice, 19(2), 139-151.

Hair, J.F., Hult, G.T.M., Ringle, C. and Sarstedt, M. (2013). A Primer on Partial Least Squares Structural Equation Modeling (PLS-SEM), Sage Publications Ltd, London.

Hair, J.F., Henseler, J., Dijkstra, T., Sarstedt, M., Ringle, C., Diamantopoulos, A., Straub, D., Ketchen, D., GTM, H. and Calantone, R. (2014). Common beliefs and reality about partial least squares: comments on Rönkkö and Evermann, Organizational Research Methods, 17(2), 182-209.

Hair, J. F., Hult, G. T. M., Ringle, C. M., and Sarstedt, M. (2017). A Primer on Partial Least Squares Structural Equation Modeling (PLS-SEM), 2nd Ed., Sage: Thousand Oaks.

Henseler, J., Ringle, C.M. and Sarstedt, M. (2015). A new criterion for assessing discriminant validity in variance-based structural equation modeling, Journal of the Academy of Marketing Science, 43(1), 115-135.

Henseler, J., Ringle, C.M. and Sinkovics, R.R. (2009). The use of partial least squares path modeling in international marketing, in Sinkovics, R.R. and Ghauri, P.N. (Eds), New Challenges to International Marketing, Emerald Group Publishing Limited.

Huo, B., Ye, Y., Zhao, X. \& Zhu, K. (2019). Supply chain quality integration: A taxonomy perspective. International Journal of Production Economics. 207(1), 236-246.

Jacobs, E. \& Mafini, C. (2019). Transactional leadership, supply chain quality and business performance in the fast-moving consumer goods industry. Journal of Transport and Supply Chain Management. 13(0), a442.

Kuhnert, K.W. \& Lewis, P. (1987). Transactional and transformational leadership: A constructive/developmental analysis, Academy of Management Review. 12(4), 648-657.

Le T. T, Nguyen T. A., Phan T. T. H, Tran M. D, Phung X. T, Tran T. T \& Giao K. N. (2019). Impact of corporate social responsibility on supply chain management and financial performance in Vietnamese garment and textile firms. Uncertain Supply Chain Management, 7(3), 679-690.

Lin, C., Kuei, C. \& Chai, K., (2013). Identifying critical enablers and pathways to high performance supply chain quality management. International Journal of Operations \& Production Management. 33(3), 347-370.

Mikelsone, E. \& Liela, E., (2016). Idea management and organisational effectiveness: A research gap. Journal of Business Management. 12, 4-23.

Phan T. T. H, Doan X. T., Nguyen T. T. T. (2019). The impact of supply chain practices on performance through supply chain integration in textile and garment industry of Vietnam. Uncertain Supply Chain Management, 8(1), $175-186$.

Penno, M.C. (2017). A positive theory of accounting-based management by exception (May 31, 2017), viewed 27 January 2019

Robbins, S.P., Judge, T.A. \& Sanghi, S. (2007). Organizational behavior, 12th edn., Pearson, Delhi.

Smith, T.M. \& Reece, J.S., (1999). The relationship of strategy, fit, productivity, and business performance in a services setting. Journal of Operations Management. 17(2), 145-161. 
Suhong, L., Ragu-Nathan, B., Ragu-Nathan, T.S. \& Rao, S.S., (2006). The impact of supply chain management practices on competitive advantage and organizational performance. Omega 34(2), 107-124.

Teoman, S. \& Ulengin, F. (2017). The impact of management leadership on quality performance throughout a supply chain: an empirical study. Total Quality Management \& Business Excellence, DOI: 10.1080/14783363.2016.1266244

Uwamahoro, A. (2018). Effects of supply chain integration on performance: An analysis of manufacturing firms in Rwanda. East Africa Research Papers in Business, Entrepreneurship and Management. 3, 3-20.

Yukl, G. (2013). Leadership in organisations, 8th edn., Pearson Education, Harlow, Essex.

Yu, Y. \& Huo, B., (2018). Supply chain quality integration: Relational antecedents and operational consequences. Supply Chain Management: An International Journal, 23(3), 188-206.

Zulkiffli, S. \& Perera, N. (2011). A literature analysis on business performance for SMEs - Subjective or objective measures? Proceedings of the 2011 SIBR Conference on Interdisciplinary Business and Economics Research, Society of Interdisciplinary Business Research, Bangkok, Thailand, June 16-18, 2011, pp. 1-9.

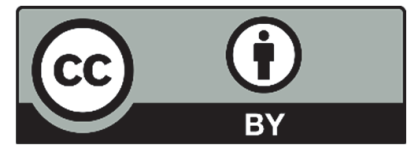

(C) 2020 by the authors; licensee Growing Science, Canada. This is an open access article distributed under the terms and conditions of the Creative Commons Attribution (CC-BY) license (http://creativecommons.org/licenses/by/4.0/). 